\title{
Hydration in Alkali-silicate Glasses Studied by Two Dimensional Multi-Quantum Magic Angle Spinning
}

\author{
Hirotsugu Masui ${ }^{\mathrm{a}}$, Danping Chen ${ }^{\mathrm{a}}$, Tomoko Akai ${ }^{\mathrm{a}, \mathrm{b}}$, and Tetsuo Yazawa ${ }^{\mathrm{b}}$ \\ ${ }^{\mathrm{a}}$ Conversion and Control by Advanced Chemistry, PRESTO, JST, and ${ }^{\mathrm{b}}$ Special Division of Green \\ Life Technology, AIST Kansai, 1-8-31, Midorigaoka, Ikeda, Osaka, 563-8577, Japan \\ Reprint requests to Prof. T. A.; Fax: +81-727-51-9627, E-mail: t-akai@ aist.go.jp
}

Z. Naturforsch. 57 a, 473-478 (2002); received January 23, 2002

Presented at the XVIth International Symposium on Nuclear Quadrupole Interactions,

Hiroshima, Japan, September 9-14, 2001.

\begin{abstract}
The hydration in $\mathrm{Na}_{2} \mathrm{O}-3 \mathrm{SiO}_{2}$ glass was studied by ${ }^{23} \mathrm{Na}$ Magic Angle Spinning (MAS) and 2D MQMAS NMR spectroscopy. It was found that one-dimensional MAS spectra for the hydrated glasses with more than $8.4 \mathrm{wt} \%$ water consist of two signals at around -10 and $-40 \mathrm{ppm}$. On the other hand, anhydrous glass and glass with low water content $(2.8 \mathrm{wt} \%)$ give a single resonance line at around $-10 \mathrm{ppm}$. From 2D MQMAS spectra, the isotropic chemical shift $\left(\delta_{\text {iso }}\right)$ and the quadrupole coupling frequency $\left(\nu_{\mathrm{Q}}\right)$ for two sites $(\mathrm{Na}(1)$ and $\mathrm{Na}(2))$ were estimated: $\delta_{\text {iso }}=4.2 \mathrm{ppm}$ and $\nu_{\mathrm{Q}}=0.6 \mathrm{MHz}$ for $\mathrm{Na}(1)$ and $\delta_{\text {iso }}=10.2 \mathrm{ppm}$ and $\nu_{\mathrm{Q}}=1.3 \mathrm{MHz}$ for $\mathrm{Na}(2)$. These results are discussed together with our previous results of ${ }^{29} \mathrm{Si}$ and ${ }^{1} \mathrm{H}$ NMR, and infrared spectra. It is speculated that $\mathrm{Na}(1)$ may exist in a similar environment as that in anhydrous sodium-silicate glasses, while $\mathrm{Na}(2)$ may be attached directly to water molecules.
\end{abstract}

Key words: Glass; Hydration; ${ }^{23} \mathrm{Na}$; 2D MQMAS.

\section{Introduction}

It is well known that incorporation of water in vitreous silicates affects the physical and chemical properties of the glasses [1]. Much effort has been made to understand the mechanism of this process not only in the field of glass science but also in the field of geology. However, this mechanism is not well understood. Even the fundamental question whether the silicate glass network is depolymerized by water incorporation is still open.

NMR is a powerful method to investigate the structural change of glasses by their reaction with water, and therefore many works have already appeared. Zheng et al. [2] have concluded that depolymerization of the glass network occurs on the reaction of glass with water, and as a consequence $\mathrm{Si}-\mathrm{OH}$ units are formed. Zotov and Keppler [3] measured ${ }^{29} \mathrm{Si}$ Magic Angle Spinning (MAS) NMR of hydrated glass and found breakage of the $=\mathrm{Si}-\mathrm{O}-\mathrm{Si}=$ linkage with water content. On the other hand, some authors insist that such depolymerization does not occur. Kohn et al. [4] proposed that $\mathrm{Si}-\mathrm{OH}$ units are formed not from the depolymerization but from the ion-exchange process between $\mathrm{Na}^{+}$and $\mathrm{H}^{+}$. Pandya et al. [5] investigated sodium-silicate glasses corroded by water for 6 years at low temperature. They found that the glasses contain high amounts of molecular water, but there is not any significant change in ${ }^{29} \mathrm{Si}$ MAS spectra, implying that there is not any significant depolymerization of the silicate network. In discussing the problem, it is very important to note that hydration does not proceed by a single reaction but by several different reactions. A typical model was proposed by Charles [6]. In that model, hydration of glass proceeds in three steps:

$$
\begin{aligned}
& \equiv \mathrm{Si}-\mathrm{O}-\mathrm{Na}^{+}+\mathrm{H}_{2} \mathrm{O} \rightarrow \equiv \mathrm{Si}-\mathrm{OH}+\mathrm{Na}^{+}+\mathrm{OH}^{-}, \\
& \equiv \mathrm{Si}-\mathrm{O}-\mathrm{Si} \equiv+\mathrm{OH}^{-} \rightarrow \equiv \mathrm{Si}-\mathrm{OH}+\equiv \mathrm{Si}-\mathrm{O}^{-} \\
& \equiv \mathrm{Si}-\mathrm{O}^{-}+\mathrm{H}_{2} \mathrm{O} \rightarrow \equiv \mathrm{Si}-\mathrm{OH}+\mathrm{OH}^{-}
\end{aligned}
$$

It can be seen that, once reaction (1) proceeds, the depolymerization takes place continuously by the repetition of (2) and (3). In addition to such reactions, the recombination

$$
2 \mathrm{Si}-\mathrm{OH} \rightarrow=\mathrm{Si}-\mathrm{O}-\mathrm{Si}=+\mathrm{H}_{2} \mathrm{O}
$$


may become important especially, when the concentration of Si-OH and $\mathrm{H}_{2} \mathrm{O}$ becomes high [7]. Most researchers who insist on the absence of structural changes with hydration seem to use hydrated glasses with high water content (30wt\%), while those stressing the decomposition examine glass with low water content $(<10 \mathrm{wt} \%)$. It is a reasonable hypothesis that the different views on the structural changes arise because different stages of the reaction are observed. To clarify this point, we investigated hydrated sodium silicate glasses with a wide range of water content $(0$ to $30 \mathrm{wt} \%)$ at low temperature $\left(<100{ }^{\circ} \mathrm{C}\right)$, using ${ }^{29} \mathrm{Si},{ }^{1} \mathrm{H}$ NMR and Infrared spectra [8]. We have shown that the glass network decomposes slightly at the initial stage of hydration, and that significant recombination of $\mathrm{Si}-\mathrm{OH}$ occurs above $20 \mathrm{wt} \%$ of water content. The result suggests that the above hypothesis may be correct. However, more information is necessary to discuss the hydration mechanism in this system. In particular, knowledge of the chemical state of sodium is of importance.

High speed ${ }^{23} \mathrm{Na}$ Magic Angle Spinning (MAS) NMR is helpful in obtaining information on the sodium environment, but recently two dimensional Multi-Quantum MAS (2D MQMAS) NMR [9] has proven to be more informative in elucidating the environment of quadrupolar nuclei. ${ }^{27} \mathrm{Al}[10-14],{ }^{11} \mathrm{~B}$ [15 - 17], ${ }^{17} \mathrm{O}\left[17\right.$ - 20], and ${ }^{23} \mathrm{Na}[10-12,14,21]$ MQMAS spectra have already been applied to study the structure of glasses.

In the present study, the hydration mechanism in sodium silicate glasses hydrated at low temperature is investigated using high resolution ${ }^{23} \mathrm{Na} N \mathrm{NMR}$ spectroscopy. ${ }^{23} \mathrm{Na} 2 \mathrm{D}$ MQMAS NMR as well as the conventional ${ }^{23} \mathrm{Na}$ MAS NMR is applied to examine the chemical state of sodium.

\section{Experimental}

Anhydrous glass of composition $\mathrm{Na}_{2} \mathrm{O}-3 \mathrm{SiO}_{2}$ was prepared by melting a stoichiometric mixture of $\mathrm{Na}_{2} \mathrm{CO}_{3}$ and $\mathrm{SiO}_{2}$ at $1300{ }^{\circ} \mathrm{C}$ for $4 \mathrm{~h}$ in a Pt crucible. Hydrated glasses with various water contents were prepared by exposing the glass powder (125 $250 \mu \mathrm{m}$ ) to saturated water vapor at $80^{\circ} \mathrm{C}$ for different times. The weight gain during the hydration process was measured and used as the water content of the glass. Figure 1 shows the change of water content with the hydration time. The sample became totally gel-like after $6 \mathrm{~h}$.

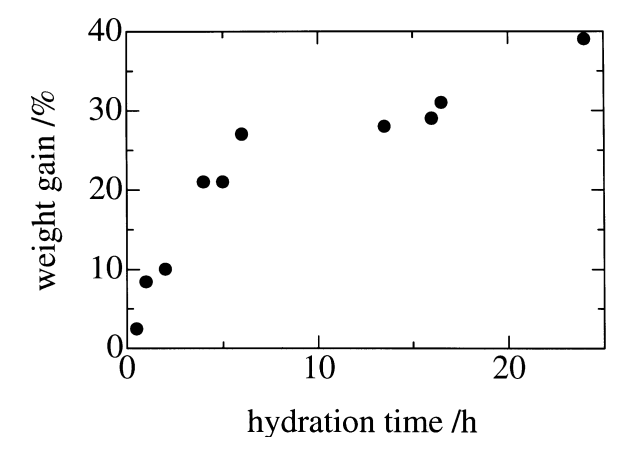

Fig. 1. Weight gain of powder $\mathrm{Na}_{2} \mathrm{O}-3 \mathrm{SiO}_{2}$ glass as a function of hydration time. The glass is hydrated at $80{ }^{\circ} \mathrm{C}$ in saturated water vapor.

All ${ }^{23} \mathrm{Na}$ MAS NMR spectra were measured on a Chemagnetics CMX-200 spectrometer with $\nu_{0}=$ $52.9718 \mathrm{MHz}\left(B_{0}=4.7 \mathrm{~T}\right) . \mathrm{NaCl}(1 \mathrm{M}$ aq.) was used as a frequency reference. 1D MAS spectra were acquired using a single pulse of typically $1 \mu \mathrm{s}$ with repetition time of $1 \mathrm{~s}$. The spinning speed was set to $10 \mathrm{kHz}$. The signal was typically registrated 144 times.

To obtain 2D MQMAS spectra, the Z-filtering 3pulse sequence and hypercomplex acquisition method was used to observe pure absorption spectra, following the procedure of Massiot et al. [22]. The lengths of the first and the second pulses and the amplitude of the third pulse were carefully optimized to maximize the signal without distortion. Typical pulse lengths were $4.2,1.4$, and $10 \mu$ s for the first, second, and third pulses, respectively. The delay time between the first and second pulse $\left(d w_{2}\right)$ was set so as to $d w_{2}=\left(1 / 4 \nu_{\mathrm{r}}\right)$, where $\nu_{\mathrm{r}}$ is the sample rotation frequency [23]. Dwell times for $t_{1}$ - and $t_{2}$-dimension were 25 and $9.7 \mu \mathrm{s}$, respectively. 384 or 768 transients of 256.48 data points were acquired. Zero-filling to 128 points in $t_{1}$-dimension and line-broadening of $200 \mathrm{~Hz}$ were employed. Proton decoupling [24] was not effective in enhancing the resolution of the MQMAS spectra.

\section{Results}

Figure 2 shows variation of ${ }^{23} \mathrm{Na}$ MAS NMR spectra in $\mathrm{Na}_{2} \mathrm{O}-3 \mathrm{SiO}_{2}$ glasses with hydration time. In the anhydrous sample an asymmetric absorption, the maximum of which is $-10 \mathrm{ppm}$, is observed. This pattern is typical and often observed [4, 10, 25] for ${ }^{23} \mathrm{Na}$ in glasses. In the glasses with low water content (2.4wt\%, Fig. 2(b)), no significant change was 


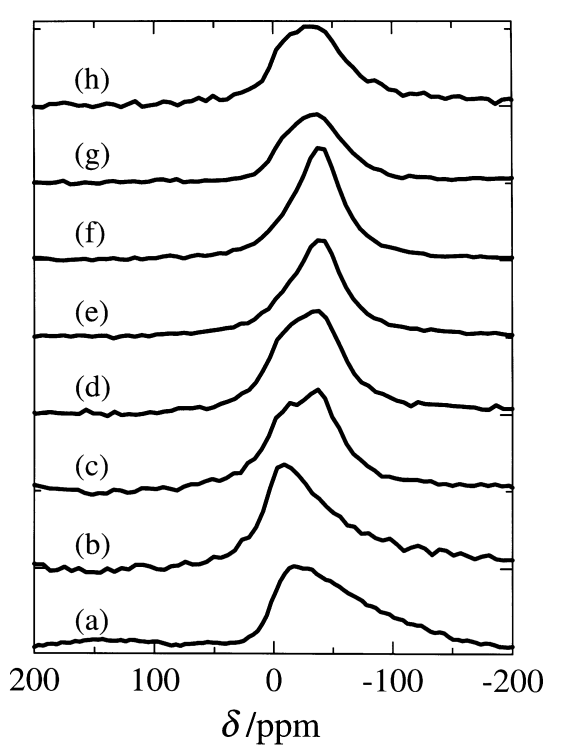

Fig. 2. ${ }^{23} \mathrm{Na}$ MAS NMR spectra of $\mathrm{Na}_{2} \mathrm{O}-3 \mathrm{SiO}_{2}$ glasses. (a) anhydrous sample. The glasses were hydrated at $80^{\circ} \mathrm{C}$ for (b) $30 \mathrm{~min}$, (c) $1 \mathrm{~h}$, (d) $2 \mathrm{~h}$, (e) $5 \mathrm{~h}$, (f) $6 \mathrm{~h}$, (g) 16.5 , and (h) $24 \mathrm{~h}$. The content of water in the glass is (b) $2.4 \mathrm{wt} \%$, (c) $8.4 \mathrm{wt} \%$, (d) $10 \mathrm{wt} \%$, (e) $21 \mathrm{wt} \%$, (f) $27 \mathrm{wt} \%$, (g) $31 \mathrm{wt} \%$, and (h) $39 \mathrm{wt} \%$.

observed in the spectra, indicating that the sodium environment does not change greatly. With further increase of water content $(>8.4 \mathrm{wt} \%$, Fig. 2(c)), a new peak, centered at around $-40 \mathrm{ppm}$ appears. The intensity of this peak increases until the water content reaches $27 \mathrm{wt} \%$ (Fig. 2(f)). The peak at around -10 ppm again appears above $30 \mathrm{wt} \%$ of water content (Fig 2(g) and (h)).

To estimate the fraction of the two sites observed in hydrated glasses, we attempted to fit the spectra in Figs. 2(c) - (h), assuming that these two sites are approximately represented by two Gaussian shapes centered at $-10 \mathrm{ppm}$ and $-40 \mathrm{ppm}$. The position, width and proportion of the area obtained from the fittings are shown in Figure 3.

The temperature dependence of ${ }^{23} \mathrm{Na}$ MAS spectra for the sample (39\%, Fig. 2(h)) is shown in Figure 4. As the temperature is lowered, the peak at around -40 ppm disappears, and finally a similar pattern as that of anhydrous glass is observed at $-50{ }^{\circ} \mathrm{C}$.

We carried out 2D ${ }^{23} \mathrm{Na}$ MQMAS NMR experiments to obtain more information on the environment of the two sites of $\mathrm{Na}$ observed in MAS spectra. In Fig. 5, 2D ${ }^{23} \mathrm{Na}$ MQMAS spectra of the anhydrous and the hydrous glass with high water content $(39 \mathrm{wt} \%$,
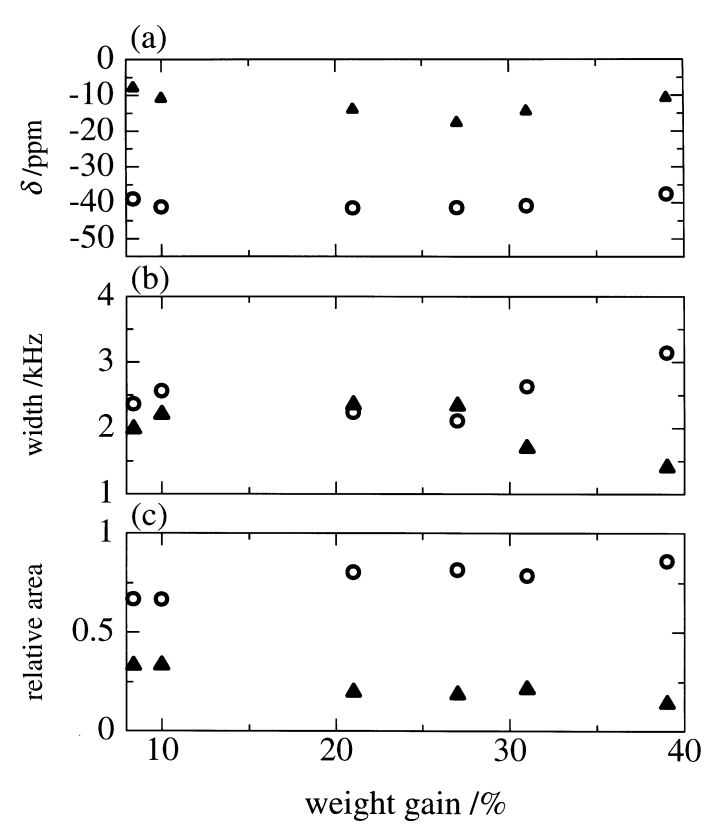

Fig. 3. The variation of the peak position, line width and relative area as a function of water content obtained, assuming two Gaussian peaks centered at $-10 \mathrm{ppm}$ (А) and $-40 \mathrm{ppm}$ (o) (see the text).

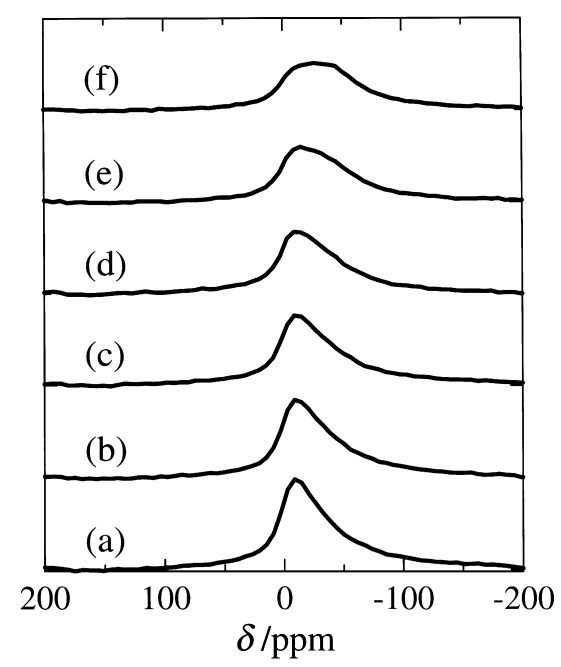

Fig. 4. Temperature dependence of ${ }^{23}$ Na MAS NMR spectrum of hydrous glass ( $24 \mathrm{~h}, 39 \%$; (h) in Figure 2). (a) $-80{ }^{\circ} \mathrm{C}$, (b) $-50{ }^{\circ} \mathrm{C}$, (c) $-30{ }^{\circ} \mathrm{C}$, (d) $-10{ }^{\circ} \mathrm{C}$, (e) $10{ }^{\circ} \mathrm{C}$, and (f) $27^{\circ} \mathrm{C}$.

Figure 2(h)) are presented. The $F_{2}$ axis (horizontal) corresponds to the usual MAS dimension, and the $F_{1}$ axis (vertical) the isotropic one. All the spectra, both in $F_{1}$ and $F_{2}$ dimensions, are asymmetric [26]. One 


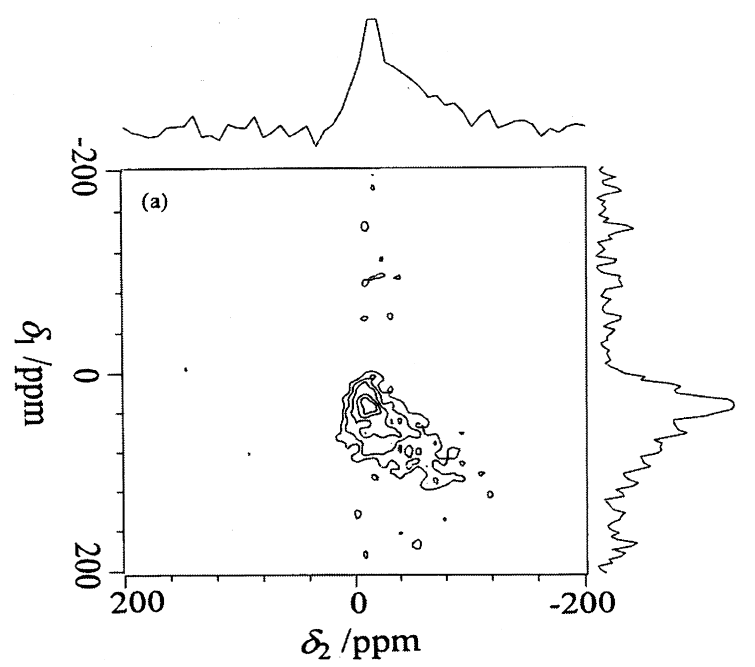

Table 1. The quadrupole coupling frequency $\left(\nu_{\mathrm{Q}}\right)$ and the isotropic chemical shift $\left(\delta_{\text {iso }}\right)$ for ${ }^{23} \mathrm{Na}$ in the hydrous glass (39\%) obtained from Figure 5(b).

\begin{tabular}{ccccc}
\hline & $\delta_{1} / \mathrm{ppm}$ & $\delta_{2} / \mathrm{ppm}$ & $\nu_{\mathrm{Q}} / \mathrm{MHz}$ & $\delta_{\text {iso }} / \mathrm{ppm}$ \\
\hline $\mathrm{Na}(1)$ & 26.8 & -10.2 & 0.6 & 4.2 \\
$\mathrm{Na}(2)$ & 91.6 & -45.6 & 1.3 & 10.2 \\
\hline
\end{tabular}

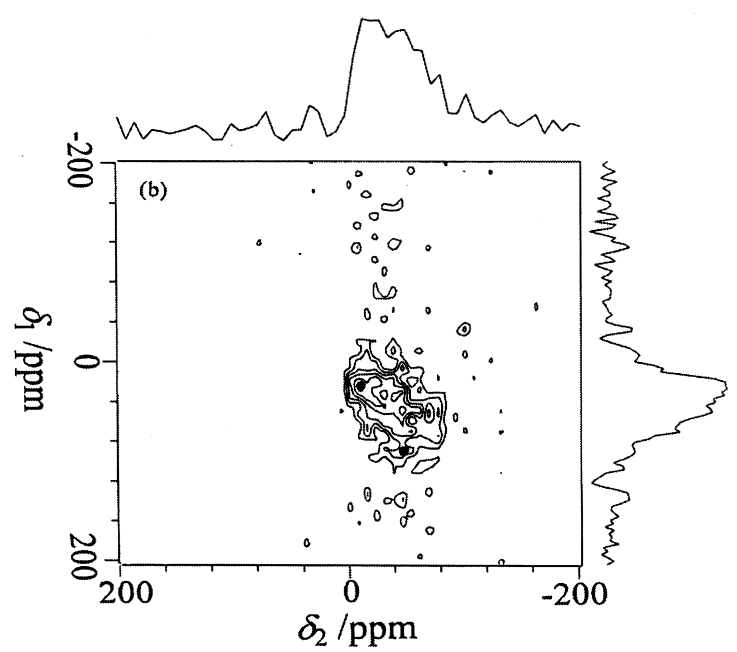

Fig. 5. ${ }^{23} \mathrm{Na}$ MQMAS spectra for (a) anhydrous glass and (b) hydrated glass (24 h, 39\%). The lowest level of contour lines is $30 \%$ of the maximum point.

of the possible reasons for this asymmetry is that the efficiency of the triple quantum excitation depends strongly on the strength of the quadrupolar coupling constant, leading to the asymmetric spectra [12]. It is also possible that the distribution of $\delta_{\text {iso }}$ and $\nu_{\mathrm{Q}}$ is asymmetric in the case of sodium in glasses $[11,12]$. Figure 6 shows the variation of the $F_{1}$ projection with the water content in the sample. The intensity of the $F_{1}$ projection in $50-100 \mathrm{ppm}$ seems to increase with the hydration time. In Fig. 5(b), the 2D signal, corresponding to this region, has a maximum at about $-40 \mathrm{ppm}$ in $F_{2}$ (see Fig. 5). With decrease in temperature, the intensity in the region between $50 \mathrm{ppm}$

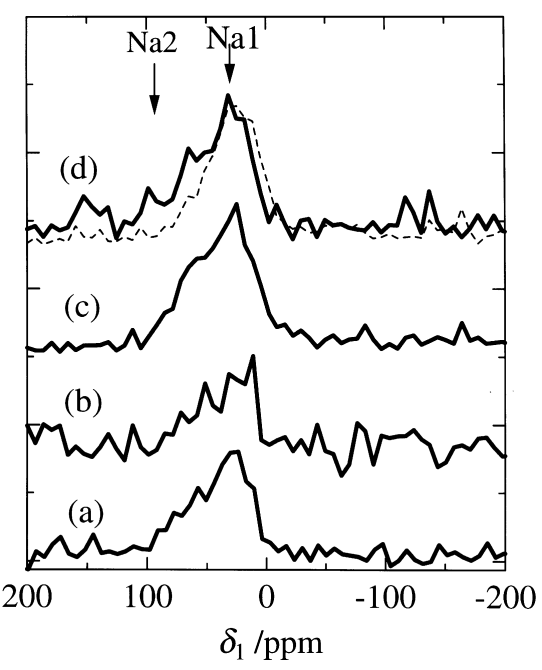

Fig. 6. $F_{1}$ projection of 2D MQMAS spectrum for (a) anhydrous glass and hydrous glass of with water concentration of (b) $2.4 \%$, (c) $10 \%$, and (d) $39 \%$.

to $100 \mathrm{ppm}$ in $F_{1}$ decreases, as shown by the dashed line. This corresponds to the fact that the signal of $\mathrm{Na}(2)$ in MAS spectra disappears at low temperature.

It was possible to find the point where the signals from $\mathrm{Na}(1)$ or $\mathrm{Na}(2)$ reach maxima both in the $F_{1}$ and $F_{2}$ dimension. These maxima are shown by closed circles in Fig. 5(b), and their chemical shifts are listed in Table 1. From these values we estimated the isotropic chemical shift $\left(\delta_{\text {iso }}\right)$, and the nuclear quadrupole coupling frequency $\left(\nu_{\mathrm{Q}}\right)$ for $\mathrm{Na}(1)$ and $\mathrm{Na}(2)$, using the procedure [10] as follows.

For $I=3 / 2$, the center of gravity of a signal in $F_{1}$ and $F_{2}$ dimension $\left(\delta_{1}, \delta_{2}\right)$ is expressed as

$$
\begin{aligned}
& \delta_{1}=\frac{17}{8} \delta_{\text {iso }}+\frac{10^{6}}{8} \frac{\nu_{\mathrm{Q}}^{2}}{\nu_{0}^{2}}, \\
& \delta_{2}=\delta_{\text {iso }}-\frac{10^{6}}{10} \frac{\nu_{\mathrm{Q}}^{2}}{\nu_{0}^{2}},
\end{aligned}
$$

where $\nu_{0}$ is the Larmor frequency. Hence, $\delta_{\text {iso }}$ and $\nu_{\mathrm{Q}}$ for each site can be obtained from the experimental 
values of its $\delta_{1}$ and $\delta_{2}$ by solving (5) and (6). The parameters thus obtained are also listed in Table 1.

\section{Discussion}

In the present work, two sites were found in hydrated glasses $(>8.4 \mathrm{wt} \%)$, and their isotropic chemical shifts and quadrupolar coupling frequency are determined from ${ }^{23} \mathrm{Na} 2 \mathrm{D}$ MQMAS NMR spectra. The values of $\delta_{\text {iso }}$ and $\nu_{\mathrm{Q}}$ for ${ }^{23} \mathrm{Na}$ in sodium silicates and sodium hydrous silicates have already been determined by a few authors [27, 28]. Angeli et al. [12] investigated a series of sodium silicate, sodium alumino-silicate crystals and found a good relationship between the bond distance $\mathrm{Na}-\mathrm{O}\left(d_{\mathrm{Na}-\mathrm{O}}\right)$ and $\delta_{\text {iso }}$,

$$
d_{\mathrm{Na}-\mathrm{O}}(\AA)=-0.0119 \delta_{\text {iso }}+2.5912 .
$$

Using (7), the Na-O distance for $\mathrm{Na}(1)$ and $\mathrm{Na}(2)$ is estimated to be $2.54 \AA$ and $2.47 \AA$, respectively. Angeli has shown that the average $\mathrm{Na}-\mathrm{O}$ distance in sodium silicate glass is about $2.5 \AA$, so that the values obtained here are reasonable. Unfortunately, such a difference is not enough to specify the chemical states because various possible species of sodium-silicate or sodium-hydrosilicate have the $\mathrm{Na}-\mathrm{O}$ distance between $2.4 \AA$ to $2.6 \AA$. The difference of $\nu_{\mathrm{Q}}$ for the two sites are not enough to distinguish the chemical states either, as $\nu_{\mathrm{Q}}$ for many types of sodium silicate crystals and sodium hydroxide overlaps within this region of $\nu_{\mathrm{Q}}$. Although the chemical states were not well determined by the use of the 2D MQMAS spectra, the valuable information has been obtained that $\mathrm{Na}(2)$ has a shorter $d_{\mathrm{Na}-\mathrm{O}}$ and larger $\nu_{\mathrm{Q}}$ than $\mathrm{Na}(1)$.

We further discuss the origin of the two sites of sodium, by considering again the variation of the ${ }^{23} \mathrm{Na}$ MAS spectra with water content (Fig. 2). Since the peak position of $\mathrm{Na}(1)$ is similar to that in anhydrous glass, $\mathrm{Na}(1)$ exists in similar environments in the anhydrous bulk glass, being attached to non-bridging oxygen, $\equiv \mathrm{Si}^{-} \mathrm{O}^{-}$. On the other hand, $\mathrm{Na}(2)$ must be related to the site interacting with water incorporated in the glass because the signal for $\mathrm{Na}(2)$ becomes prominent only for the glasses containing a relatively high amount of water $(>8.3 \mathrm{wt} \%)$.

Our previous results on infrared and ${ }^{29} \mathrm{Si},{ }^{1} \mathrm{H}$ NMR spectra [8] have shown that a structural change in the glass matrix occurs, depending on the water concentration incorporated in the glass: i) depolymerization of the -O-Si-O- network takes place above $3 \%$ water, ii) a mobile proton, originated from molecular $\mathrm{H}_{2} \mathrm{O}$, exists in glass with a higher water content $(>7$ - $8 \mathrm{wt} \%$ ). The mobile proton may exist in the microphase of water in the micropores created by the decomposition of the glass network, iii) a significant recombination of $\equiv \mathrm{Si}-\mathrm{OH}$ occurs above $20 \%$ of water, which is the reason for the gelation. Considering such structural changes, we tentatively assign $\mathrm{Na}(2)$ to $\mathrm{Na}^{+}$ existing in a water microphase having relatively high mobility. It may be reasonable that sodium ions have much shorter bond lengths with oxygen and higher nuclear quadrupole coupling frequencies because the polarizability of $\mathrm{OH}^{-}$should be much stronger than that of $\mathrm{Si}^{-} \mathrm{O}^{-}$. This assignment for the site $\mathrm{Na}(2)$ is further supported by the fact that the signal from $\mathrm{Na}$ (2) disappears with decreasing temperature. It is very likely that water in a microphase freezes below $0{ }^{\circ} \mathrm{C}$, and, as a result, sodium ions are segregated from the water phase. The segregated sodium should attach to a $\equiv \mathrm{Si}^{-} \mathrm{O}^{-}$unit by ion exchange with $\mathrm{H}$ existing as $\mathrm{Si}-\mathrm{OH}$.

The local structure of $\mathrm{Na}(2)$ in the hydrated glass is not well specified at present, but it may be similar to that in some hydrous sodium silicate crystals having layered structure, where sodium ions are coordinated by the water and exist between silicate layers (see e. g. [21]). In the case of hydrated glasses, sodium and water may exist in micropores, the sizes of which are larger than in the water layers of the crystals. The size of the micropores may be large enough to give rise to the mobility of sodium and water observed in the experiments.

In the present study, two different species of sodium were found by using ${ }^{23} \mathrm{Na}$ MAS and MQMAS spectra. The isotropic chemical shift and the quadrupole coupling frequency of each site were successfully determined from MQMAS spectra. A still remaining question is how a $\mathrm{Na}^{+}$ion coordinates to a water molecule. ${ }^{23} \mathrm{Na} \leftarrow{ }^{1} \mathrm{H}$ CP MQMAS [29, 30] and MQMAS / HETCOR [31] experiments should be very helpful in answering the question, which is left for future study.

\section{Conclusion}

Hydration processes at low temperatures in $\mathrm{Na}_{2} \mathrm{O}$ $3 \mathrm{SiO}_{2}$ glasses were investigated by ${ }^{23} \mathrm{Na} \mathrm{NMR} .{ }^{23} \mathrm{Na}$ MAS spectra show that there exist two sodium sites in different chemical environment in a hydrated glass 
(> 8.4wt\%). The temperature dependences of ${ }^{23} \mathrm{Na}$ MAS spectra show that the second site disappears diminishes below $0{ }^{\circ} \mathrm{C}$. From 2D MQMAS NMR spectra, it was possible to estimate the isotropic chemical shift and nuclear quadrupole coupling frequency for each site. From these results it is concluded that the second site in a hydrated glass $(>8.4 \mathrm{wt} \%)$ is associated with sodium ions attached to water molecules.

[1] R. F. Bartholomew, Treatise Mater. Sci. Tech. 22, 75 (1982).

[2] Q. Zeng, H. Nekvasil, and C. P. Grey, Geochim. Cosmochim. Acta 64, 883 (2000).

[3] N. Zotov and H. Keppler, Amer. Miner. 83, 823 (1998).

[4] S. C. Kohn, M. E. Smith, P. J. Dirken, E. R. H. van Eck, A. P. M. Kentgens, and R. Dupree, Geochim. Cosmochim. Acta 62, 79 (1998).

[5] N. Pandya, D. W. Muenow, S. K. Sharma, and B. L. Sherriff, J. Non-Cryst. Solids 176, 140 (1994).

[6] R. J. Charles, J. Appl. Phys. 29, 1549 (1958).

[7] A. Paul, "Chemistry of Glasses", Chapt. 3, Chapman and Hall, 1990.

[8] T. Akai, A. Kishigami, H. Masui, M. Yamashita, H. Yamanaka, and T. Yazawa, J. Phys. Chem. B, to be submitted.

[9] L. Frydman and J. S. Harwood, J. Amer. Chem. Soc. 117, 5367 (1995).

[10] F. Angeli, P. Faucon, T. Charpentier, J. C. Petit, and J. Virlet, Mat. Res. Soc. Symp. Proc. 506, 71 (1998).

[11] F. Angeli, T. Charpentier, P. Faucon, and J. C. Petit, J. Phys. Chem. B 103, 10356 (1999).

[12] F. Angeli, J. M. Delaye, T. Charpentier, J. C. Petit, D. Ghaleb, and P. Faucon, J. Non-Cryst. Solids 276, 132 (2000).

[13] J. F. Stebbins, S. Kroeker, S. K. Lee, and T. J. Kiczenski, J. Non-Cryst. Solids 275, 1 (2000).

[14] C. Jaeger, P. Hartmann, G. Kunath-Fandrei, O. Hirsch, P. Rehak, J. Vogel, M. Feike, H. W. Spiess, K. Herzog, and B. Thomas, Ber. Bunsen-Ges. 100, 1560 (1996).

[15] S. J. Hwang, C. Fernandez, J. P. Amoureux, J. Cho, S. W. Martin, and M. Pruski, Solid State NMR 8, 109 (1997).

\section{Acknowledgement}

We would like to thank Dr. Sugisawa, JEOL Ltd., for helpful discussions and for providing pulse programs and data processing macros on CMX. This work was supported under Conversion and Control by Advanced Chemistry, PRESTO, Japan Science and Technology Corporation (JST).

[16] S. J. Hwang, C. Fernandez, J. P. Amoureux, J. W. Han, J. Cho, S. W. Martin, and M. Pruski, J. Amer. Chem. Soc. 120, 7337 (1998).

[17] P. Zhao, S. Kroeker, and J. F. Stebbins, J. Non-Cryst. Solids, 276, 122 (2000).

[18] S. K. Lee and J. F. Stebbins, J. Phys. Chem. B 104, 4091 (2000).

[19] S. K. Lee and J. F. Stebbins, J. Non-Cryst. Solids 270, 260 (2000).

[20] Z. Xu, H. Maekawa, J. V. Oglesby, and J. F. Stebbins, J. Amer. Chem. Soc. 120, 9894 (1998).

[21] M. Hanaya and R. K. Harris, J. Mater. Chem. 8, 1073 (1998).

[22] D. Massiot, B. Touzo, D. Trumeau, J. P. Coutures, J. Virlet, P. Florian, and P. J. Grandinetti, Solid State NMR 6, 73 (1996).

[23] D. Massiot, J. Magn. Reson. A 122, 240 (1996).

[24] M. Hanaya and R. K. Harris, Solid State NMR 8, 147 (1997).

[25] H. Maekawa, T. Saito, and T. Yokokawa, J. Phys. Chem. B 102, 7523 (1998).

[26] P. R. Bodart, J. Magn. Reson. 133, 207 (1998).

[27] G. Engelhardt and H. Koller, Magn. Reson. Chem. 29, 941 (1991).

[28] H. Koller, G. Engelhardt, A. P. M. Kentgens, and J. Sauer, J. Phys. Chem. 98, 1544 (1994).

[29] J. M. Egan and K. T. Mueller, J. Phys. Chem. B 104, $9580(2000)$

[30] K. H. Lin and C. P. Grey, J. Chem. Phys. 112, 7490 (2000).

[31] S. H. Wang, S. M. De Paul, and L. M. Bull., J. Magn. Reson. 125, 364 (1997). 